\title{
Romance de primas com primas e o problema dos afetos. Parentesco e micropolítica de relacionamentos entre interlocutores tikuna, sudoeste amazônico*
}

\section{Patricia Carvalho Rosa**}

[...] Hoje vivemos um romance. Mas já vivemos tempos difíceis. Tempos de medo, de ameaças, de castigos, de fugas e negociações. [...] Agora que nossas famílias aceitam o romance, está tudo bem. [...] Moramos juntas e já pensamos em casamento. Aí o romance será compromisso mesmo: quando casa, aí você tem o papel, está de papel passado. [...] Aí teremos nossa casa de verdade. Mas acho que não poderemos morar na aldeia. [...] Isso aqui, onde vivemos, é jeito de mostrar casamento: ter filhos, a roça, a casa perto da mãe; [...] ou estudada também [...] vira, assim, gente madura; daquelas que faz comunidade. Já fizemos os filhos, antes, com os ex-maridos, garantindo a eles o jeito de magüta [...] porque o homem tikuna dá pro filho o clã, não a mulher. [...] Nesse tempo de casada, ela tinha a roça dela, a casa dela. Eu não. Saí para estudar, e meu ex não fez roça pra nossa família [...] mas acho que ali, comigo, era porque não casei porque eu queria, mas porque era preciso seguir as regras [...] gostar assim... não, eu ficava com ele por ficar; sei nem como explicar, sem gosto. Ai depois que eu conheci uma moça, era algo que me sentia bem, prazer de ficar perto dela e tudo mais. (Matchirena, agosto de 2012, Benjamin Constant)

\footnotetext{
" Recebido para publicação em 21 de setembro de 2013, aceito em 2 de outubro de 2013. Sou grata a Adriana Piscitelli e José Miguel Nieto Olivar; Flávia Melo e toda a equipe do projeto Observatório de Violência contra as Mulheres no Alto Solimões; Dany Mahecha, Vanessa Lea, Leonardo Peixoto, Sanderson Oliveira, Luciano Cardenes e às pesquisadoras do PAGU, com apreço a Natália Corazza e Laura Lowenkron.

** Doutoranda no Programa de Pós-Graduação em Antropologia Social, UNICAMP. pati.carvalho.rosa@gmail.com
}

cadernos pagu (41), julho-dezembro de 2013:77-85. 
Romance de primas com primas e o problema dos afetos

As notas etnográficas aqui apresentadas estão vinculadas à pesquisa em andamento, cujo tema abarca as micropolíticas dos afetos, tendo como objeto a produção do parentesco tikuna como processo composto por diversas modalidades de relacionamentos - casar certo ou errado, com e sem papel, ficar, namoros, romances. ${ }^{1}$ A partir de narrativas de duas interlocutoras viso colocar em debate a rentabilidade etnográfica e analítica de ocupar nossos olhares no que as protagonistas em tela têm designado como problemas dos afetos. Uma ideia sugerida como complemento narrativo às explicações consolidadas sobre a produção do parentesco tikuna, especialmente, no que tange às relações e posições de gênero na conformação de matrimônios.

O problema dos afetos é tomado na pesquisa como categoria descritiva empregada por elas para caracterizar outros conteúdos constitutivos das alianças em negociação, que não apenas aqueles previstos nas regras das nações. Esses conteúdos dizem respeito e são associados com o que dizem elas ser sentimentos, amor, prazer, desejos, vontades, mortes, medo, alegrias, tristezas. $\mathrm{O}$ que ocorre quando enlaçamos essas duas perspectivas discursivas, as regras e os afetos, num estudo sobre os modos de fazer-se parente no qual, além dos termos em relação, o sexo destes passa a ocupar lugar nas negociações? Que lugar ocupam, ou podem ocupar os conteúdos das relações que constituem, afinal, as modalidades de relacionamentos acima mencionadas?

Sugiro ainda um derradeiro caminho analítico a partir da observação atenta aos múltiplos discursos e dispositivos de poder, $e$ às diversas instituições (Foucault, 1988), que entram em jogo nas tensas negociações entre afetos e alianças. Abrem-se, então, perguntas sobre noções de "intimidade", "romantismo",

1 Utilizarei marcações em itálico sem aspas quando estiver citando ou referindome a categorias êmicas, termos ou expressões mencionadas pelos interlocutores. As palavras usadas na língua indígena serão também grafadas em itálico, seguindo a grafia e a glosa cedidas pelos próprios informantes. 
"individualidade" nos arranjos conjugais e afetivos vistos na perspectiva das trajetórias narradas, para, nesse sentido, buscar compreender de que modo se produz, micropoliticamente, a dimensão social que envolve o problema dos afetos; os sentidos de desejo, amor, prazer, medo, que o compóem.

Matchirena, mulher, tikuna ${ }^{2}$, de 33 anos, servidora municipal, está há aproximadamente sete anos com sua companheira, Mutchique'ena, tikuna, de 31, do lar, com quem reside nas proximidades de Benjamin Constant, município em que se localiza a Terra Indígena Santo Antônio, onde habitam seus parentes. Antes de assumirem o relacionamento, namoraram por um breve período, sem compromisso. Foi nesse período que aprenderam a se gostar mutuamente, e quando, então, passaram a morar juntas e a ter um romance.

O relacionamento atual foi precedido por matrimônios heterossexuais de ambas, que eram considerados certos. Segundo relatam, foram casamentos que, obrigados e sem amor, haviam sido arranjados pelos seus respectivos pais em consonância com o interesse de cada cônjuge potencial. Os ex-cônjuges, primos certos para casar, contraíram matrimônios posteriores a esses, ambos com mulheres tikuna. Os casamentos heterossexuais das interlocutoras ocorreram logo após a menarca de ambas: etapa paradigmática do ciclo de vida que as insere na categoria de mulheres casáveis, worecü, com ou sem a realização do ritual de

2 Os Tikuna, que se autodenominam magüta, são falantes de língua isolada (Soares, 1992) e são habitantes das margens do rio Solimões/Amazonas, cujo território abrange a tríplice fronteira. No lado brasileiro estima-se que habitam mais de 39 mil sujeitos, distribuídas em cerca de 100 comunidades, inseridas em 27 Terras Indígenas. No Peru, a população estimada é de 7.000 e na Colômbia é cerca de 8.000 pessoas. 
Romance de primas com primas e o problema dos afetos

puberdade. ${ }^{3}$ Desses relacionamentos nasceram seus respectivos filhos.

Matchirena relata que seu pai a ameaçava dizendo:

você vai ficar à força com ele"! Aí eu chorava pra não ficar com ele! Mas aí meu pai me mostrava um pau! Aí eu dizia: agora eu fico! Antigamente acontecia muito! Muito, muito, principalmente com as meninas que saiam do ritual da moça nova e tivessem um pretendente naquele momento. Saia da moça nova e ia logo ficando, mesmo você não querendo.

Matchirena não fez ritual.

Aqui a interlocutora joga em cena elementos que nos permitem pensar o amor e a ideia de afetos como mecanismos que elucidam trânsitos de pontos de vista e mudanças geracionais, permitindo encontrar combinações possíveis de gênero $e$ conjugalidades. Numa conversa com a mãe de Matchirena, com aproximadamente 60 anos, casada há cerca de 40 com o mesmo cônjuge, ouvi que

antigamente não tinha essas escolhas; casava-se com quem o pai mandava. [...] eu e meu velho nos juntamos por amor e aprendi a gostar dele. [...] hoje esses jovens já brigam por amor. [...] as mulheres já fazem filho errado, não tem roça; saem para estudar. [...] hoje um bom marido é aquele que tem estudo, complementa ela.

Matchirena afirma sobre os casamentos heterossexuais dela e de sua companheira: esses casamentos eram certos, apesar de não ter amor. Fizemos como desde os antigos. Nesse tempo, situa

3 Ritual de passagem feminino, conhecido no Brasil como Moça Nova, na Colômbia e no Peru como Fiesta de la pelación, em alusão a uma das etapas, quando após o período de reclusão, a púbere tem seus cabelos arrancados. Para melhores informações e ricas descrições desse ritual ver Valenzuela (2010) e Camacho (1995). 
Mutchique'ena no seu escasso português, que gostar do esposo não era a questão principal. Sua companheira diz que se cuidava, contudo, para que não se juntasse dois da mesma nação. Isso era dito wamachi. Fazer isso, conta ela, é provocar raiva nos bichos da floresta, que aparecem para consertar as coisas. Tem o bicho que chega para levar quem casa errado. Seu pai o nomina o barbudo, devido à aparência com homens brancos. De acordo com a descrição desse senhor de seus 60 e poucos anos, o barbudo chega de noite, persegue quem está casado errado, homem ou mulher, os leva embora e os mata. É um soldado de Deus.

Nesse sentido, além das entidades sobrenaturais, os n'go - dos quais fazem parte o barbudo, também chamado de yuerü -, que compõem a rede de socialidade tikuna, Matchirena faz menção às práticas de aconselhamentos levadas à cabo pelo conselho de anciões das aldeias, à presença da polícia indígena que, entre outras atribuições, fiscaliza os namoros, prende se for necessário, e ao pastor (neopentecostal). Este último teria a função também de exercer os consertos, por meio dos sermões e da conversão, tornando o sujeito alguém de corpo limpo, livre de sentimentos que o impeçam de readquirir a condição de imortalidade como prevê a filosofia nativa (Goulard, 1998; Santos, 2010).

Matchirena inverte a posição de entrevistada e argui: percebe o que tem aqui? Ela é menos tímida e com bom domínio da língua portuguesa; sua trajetória reúne experiências de cunho político, de inserção no movimento indígena local, tendo viajado por diferentes cidades do país, acompanhando antropólogos, missionários e seus parentes, tendo inclusive no currículo cursos de formação de agentes indígenas e de graduação em universidade federal. Replico-lhe, informada por meu arcabouço de leituras acerca da etnia e das literaturas etnológicas - campo de saber para o qual o tema do parentesco, da troca e reciprocidade tem notável lugar -, que haveria ali um problema de intercâmbio de termos: de homens com mulheres, para mulheres com mulheres/homens com homens. Sua resposta: 
Romance de primas com primas e o problema dos afetos

sim, tem o problemas dos clãs, das misturas erradas e dos problemas com os bichos do mato. E isso agora também virou problema da igreja, da polícia... Porque isso é problema dos afetos. [...] Uma vez escutei uma enfermeira dizer que entre a gente tem muita morte, brigas e essa coisa de tristeza "porque não sabem como resolver seus sentimentos". [...] isso vem de longe, essa coisa de casamento errado não é de agora, sempre teve, desde aqueles que fizeram a gente; [...] e tem as nações para evitar isso, que se casa errado. [...] regra não segura ninguém, mana. [...] Isso vem sendo feito entre os índios e o seringueiro, com os brancos da fronteira; [...] minha vó é cujurera: misturada com os peruanos. [...] E os romances e casamentos com pessoa do mesmo sexo é desse tipo: é errado; [...] é um amor proibido, também causa pecado.

"Amor proibido?", pergunto. Isso é quando a gente não pode estar junto com quem se gosta, porque é feio, atrapalha as relações dos nossos parentes; ou a comunidade não aceita. A [Fulana] tem a garota dela e pode estar na comunidade delas porque a família dela tem poder político, aí tudo fica diferente.[...] tem as igrejas agora que aceitam esses romances, esses amores proibidos, mas não acaba os julgamentos. [...] os jovens tem apanhado dos pais porque são gays; se matam, ficam tristes.

Com os pais de Matchirena aprendi que de acordo com a regra dos antigos, uma mulher deve-se casar com aquele a quem ela chama de tchorü ngü'ü, primo certo, idealmente os filhos da irmã do pai. Com isso, evita-se a realização de uniões incestuosas, ditas wamachi, condição moralmente negativada traduzida como pecado. Matchirena descreveu wamachi como efeito da interação de corpos feitos com substâncias similares fruto da junção de nações com atributos semelhantes. Isso resulta no que ela e seus pais mencionam serem corpos com carnes trançada. Casar-se errado, nesse contexto, provoca desgosto às entidades sobrenaturais, os n'go, e a Ta'e, demiurga responsável por controlar quem passará, após a morte, a habitar o patamar do cosmos onde estão os ancestrais, 
recuperando a condição de imortal (situação que ocorre somente se a pessoa não cometeu wamachi).

Para Matchirena e sua companheira Mutchique'ena mais do que casar com o primo/prima certa está em jogo a negociação de seus sentimentos. O relacionamento delas é um dos casos que conheci de romance entre primas e primas. Um relacionamento considerado em desalinho, por vezes proibido, não apenas por descumprimento às regras que orientam casar com pessoas de outro clã, mas porque os sexos dos termos em relação não condizem com as premissas culturais, do ponto de vista daqueles que as guardam. Para eles, casar certo refere-se aos arranjos maritais realizados entre sujeitos pertencentes a grupos classificatórios opostos e diferenciados, nominados nações ${ }^{4}$ (Nimuendaju, 1977; Goulard,1998, 2009; Oliveira Filho, 1988).

Levando em consideração o problema dos afetos, venho construindo um caminho interpretativo sobre a categoria de casar certo ou errado através do conhecimento das trajetórias de cada interlocutor. $\mathrm{O}$ que torna inteligíveis os diferentes lugares de enunciação sobre as relações pesquisadas, seus aspectos conformadores, atravessados por uma miríade de preceitos mitológicos, morais, políticos e econômicos, que instáveis e sobrepostos, desenham um mapa das micropolíticas em jogo nas negociações das experiências afetivas dos interlocutores da pesquisa. Isso permite que as análises posteriores dos dados sobre

${ }^{4}$ Nações é como se referem os interlocutores às metades exogâmicas $e$ patrilineares, as ko-ü, que se subdividem entre nações de pena e nações sem pena. A institucionalização desses termos classificatórios é explicada no mito de criação, em que os heróis culturais, os irmãos Yoi e Ipi, criaram o gênero humano e atribuíram nações aos Tikuna, gerando a partir daí dois principais grupos classificatórios que orientam a cosmologia tikuna, servindo-lhes como orientação para as regras de casamentos, casar entre si (Nimuendaju, 1977; Oliveira Filho, 1988; Goulard, 1998,2009). 
Romance de primas com primas e o problema dos afetos

a produção do parentesco tikuna não se encerrem apenas na chave das "estruturas simbólicas", compreendendo o sentido dos termos em relação somente pelas posições que ocupam no sistema de trocas. De modo complementar, os conteúdos afetivos que também preenchem de capacidades agentivas os sujeitos das trocas, produzem novos dados quando atentamos às extensões práticas dessas configurações.

Para compreender o caso apresentado como um tipo de vínculo equivocado é preciso vê-lo não apenas porque seu romance não condiz com as prescrições que as regras de fazer-se parente têm embutidas, manifestadas nas prerrogativas de construção de si mesmas como componentes calculados (consanguíneas e afins, primas ou irmãs), como corpos feitos $e$ pensados para determinados circuitos e relações. Mas porque também e, simultaneamente, estão em confronto com um conjunto de moralidades e interesses políticos e econômicos, de dispositivos de poder e de novos discursos de gestão do mundo dos prazeres, dos corpos, das alianças -, que se opõem e se articulam com os sistemas sociocosmológicos tikunas.

\section{Referências bibliográficas}

CAMACHO, Hugo. Magüta, la gente pescada por Yoi. Bogotá, Colcultura, 1995.

CARDOSO DE OliveirA, Roberto. $O$ índio e o mundo dos brancos. Campinas, SP, Ed. da Unicamp, 1996.

FouCAUlT, Michel. Historia da Sexualidade I: A vontade de saber. Rio de Janeiro, E. Graal, 1988.

GOULARD, Jean-Pierre. Les genres du corps: conceptions de la personne chez les Ticuna de la haute Amazonie. Tese de Doutorado, EHESS, Paris, 1998.

. Los tikuna. In: SANTOS Fernado \& BARCLAY Frederica (Eds.) Guía Etnográfica de la Alta Amazonía, vol. 1. Serie Colecciones Y Documentos /IFEA/CLASCO, 2009, pp.309-444. 
Gow. Peter. Of mixed blood. Kinship and History in Peruvian Amazonia. Claredon Press, Oxford, 1991.

NimuENDAJÚ, Curt. The Tükuna. Berkeley e Los Angeles, University of California Press, 1977 [1929].

OliveIRA FILHO, J.P. "O Nosso Governo": os Ticuna e o regime tutelar. São Paulo, Marco Zero, 1988.

SANTOS, Antonio Abel. Narración tikuna del origem del território y de los humanos. In: Mundo Amazônico, vol. 1. Letícia, Colômbia, IMANI/Universidad Nacional de Colombia, 2010, pp.303-313.

SOARES, Marília Facó. O suprassegmental em tikuna e a teoria fonética. Investigação da Sintaxe Tikuna. Tese de Doutorado, Instituto de Estudos da Linguagem, Universidade Estadual de Campinas, 1991.

VAlenzUelA, Hugo Ramos. El Ritual Tikuna de da pelazón en la Comunidad de Arara, sur del trapecio amazónico. Una Experiencia Etnográfica. Tesis de maestría en Estudios Amazónicos/Universidad Nacional De Colombia, Sede Amazonía, 2010. 